\title{
Theoretical analysis of a small-scale solar power system using an R-245fa Rankine cycle with a scroll and twin screw expander
}

\author{
J. Joung ${ }^{1} \&$ H. Cho ${ }^{2}$ \\ ${ }^{1}$ Graduate School of Chosun University, Chosun University, Korea \\ ${ }^{2}$ Department of Mechanical Engineering, Chosun University, Korea
}

\begin{abstract}
Due to the serious environmental pollution problems caused by the rapid industrialization of modern society, Kyoto Protocol was signed in 1997 to limit the emission of greenhouse gases. Therefore, the concept of renewable energy is being actively studied as an energy source that can replace old fossil fuels, and among these studies the research on solar power has also increased. In this study, the performance of a solar energy applied by R245fa Rankine cycles was analysed by using theoretical method according to the mass flow rate of R245fa. The result shows that the twin screw expander shows $4.8 \mathrm{~kW} /$ day under the low solar radiation and $5.8 \mathrm{kw} /$ day under the high radiation conditions. Furthermore, the efficiency of a scroll expander with R-245fa proves to be approximately $8 \%$ higher than that with a twin screw expander.
\end{abstract}

Keywords: Rankine cycle, solar collector, solar power systems, twin screw expander, scroll expander.

\section{Introduction}

After the Industrial Revolution, consumed energy per person has been gradually increased and fossil fuel consumption has been increased due to rapid technological development. For those reasons, the occurrence of abnormal climates, such as in El Nino and La Nina, has continuously increased. Many studies say that this is owing to the rise of atmospheric temperatures, caused by global warming. 
In 1985, the Vienna Convention about the regulations on production and use of ozone destruction materials to protect ozone layer was signed. In 1987, Montreal Protocol was formally accepted to restrain the use of materials of ozone depletion. In addition, in June 1992, the international regulation to reduce $\mathrm{CO}_{2}$ emission which is the main cause of global warming made each country propose a $\mathrm{CO}_{2}$ emission reduction goal.

For these reasons, energy development and research on alternative energy sources that could replace fossil fuels has accelerated. In particular, the interest in renewable energy as an alternative energy has increased dramatically. Solar energy among renewable energy is pollution-free energy. It has a lot of advantages including that it is possible to obtain the highest energy per unit area and the geographical distribution of energy source is more equal than that of fossil fuel. A solar collecting system is a heat energy transition or storage of energy through the absorption of radiation energy from the sun.

An Organic Rankine Cycle (ORC) is a power generating system that used low temperature heat sources $\left(60-200^{\circ} \mathrm{C}\right)$ that are unsuitable for steam generation. However, it is enough to operate an ORC cycle because the organic refrigerant has a low boiling temperature. Thus, ORC has an advantage that it is possible to generate power using low temperature by using some working fluids such as Freon or a hydrocarbon-type refrigerant.

In a recent study, Du et al. [1] developed a stable and reliable experimental platform that can satisfy the demands of experimental studies on heat pipe solar collectors. Hull [2] investigated the heat transfer factors and thermal efficiency of a heat pipe absorber array connected to a common manifold, and predicted that an array with fewer than 10 heat pipes has significantly less efficiency than a conventional flow-through collector. Bamgbopa and Uzgoren [3] reported that the ORC unit under investigation uses R245fa as the working fluid, for which a regression-based approach was implemented to evaluate its state properties.

In this study, the performance of ORC with a scroll and twin screw expander which connects to solar collector system was analyzed according to the average annual solar radiation and outdoor temperature in Gwang-ju, Korea. Through this study, the basic analytical data for system optimization and performance characteristics according to operating conditions can be presented.

\section{System modelling}

Fig. 1 shows a schematic diagram of the Rankine cycle using R245fa as working fluid and solar collector system. The solar collecting system consists of a pump, solar collectors, heat exchangers, and an assistance tank. A pump supplies working fluid (water) to solar collectors. Working fluid absorbs thermal energy in the solar collectors, and deliveries it to the heat exchanger in the assistance tank. After storing heat in the assistance tank, it flows to the pump and circulates.

The Rankine cycle using R245fa consists of a pump, evaporator, expander, condenser, and generator. R245fa discharges by a pump and exchanges thermal energy with the working fluid (water) from the solar collector in the evaporator. In the evaporator, it is boiled and flows into the expander, and then it generates 
power through an expansion process in the expander. After then, it is condensed in the condenser. The generated power at the expender can be converted into electricity by using the generator and is then saved in a container or supplied to the house.

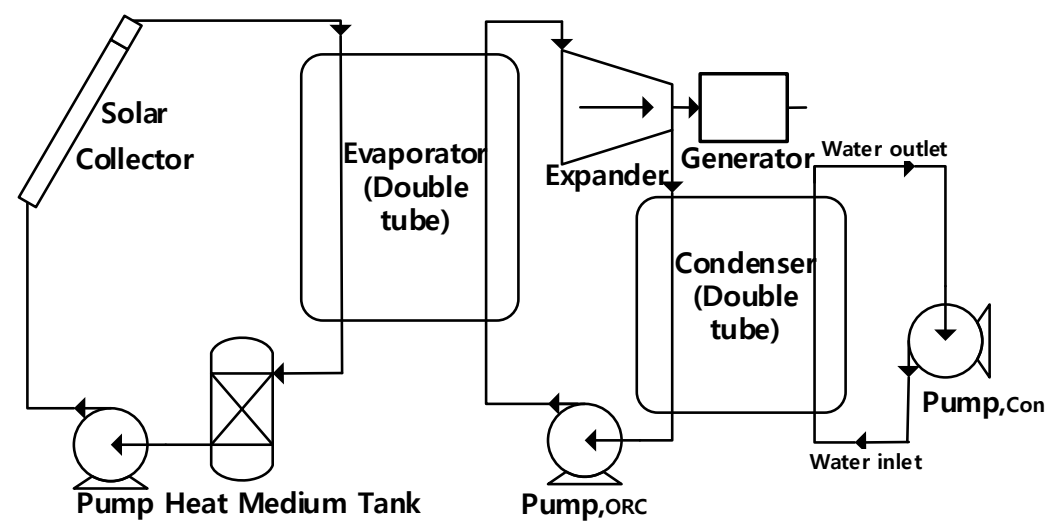

Figure 1: Schematic diagram of R245fa generator system.

Table 1 shows the design specifications of a solar collector. A solar collector has 20 double evacuate tubes, and 8 solar collectors in series are composed of a single set. In this study, two solar collector sets were used in parallel and the total area is $31.68 \mathrm{~m}^{2}$. The working fluid of the solar collector is assumed as water and the mass flow rate of water was set by $0.03 \mathrm{~kg} / \mathrm{s}$.

In this study, the subcooling at the pump inlet was set at $5^{\circ} \mathrm{C}$, and the inlet temperature and pressure were assumed to be $20^{\circ} \mathrm{C}, 147.8 \mathrm{kPa}$, respectively. The superheat at the evaporator in December was set to $5^{\circ} \mathrm{C}$, and the output temperature and pressure were assumed as $75^{\circ} \mathrm{C}, 609.7 \mathrm{kPa}$, respectively.

Table 1: Specifications of solar collector.

\begin{tabular}{c|c}
\hline Item & Specification \\
\hline Type & Evacuate tube with heat pipe \\
\hline Area & $31.68 \mathrm{~m}^{2}(8$ ea $* 2 \mathrm{row})$ \\
\hline Mass flow rate of water & $0.03 \mathrm{~kg} / \mathrm{s}$ \\
\hline
\end{tabular}

\section{Analysis method and procedure}

Fig. 2 shows a schematic diagram of the working fluid flow in a condenser of a double evacuate tube solar collector. After working fluid is passing through each tube of the collector and it flows into manifold. It is heated by a heat exchanger at a condenser of the heat pipe and then discharges. 


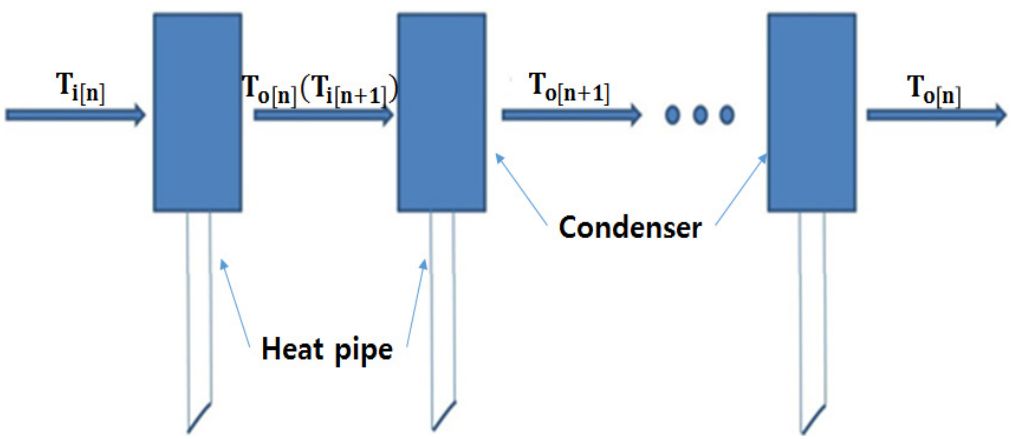

Figure 2: Schematic of fluid flow in the condenser part.

The recovery rate of useful energy, which is gained by a single pipe, can be presented by eqn. (1).

$$
Q_{u}=A_{a} F^{\prime}\left[G(\tau a)_{e}-U_{L}\left(T_{h p}-T_{a}\right)\right]
$$

where $T_{a}$ is ambient temperature, $A_{a}$ is the heat transfer area connected with heat pipe in the tube. $(\tau \alpha)_{e}$ is the effective transmittance-absorptance product, and $U_{L}$ is the solar collector heat transfer loss coefficient. The useful energy transferred in the form of heat by fluid flowing in the manifold can be written as

$$
\begin{gathered}
T_{h p[n]}=T_{a}+\frac{G(\tau \alpha)}{U_{L}}-\frac{T_{o[n]} T_{i[n]}}{N T U_{h p[n]}} \\
T_{o[n]}=T_{i}+\frac{\varepsilon_{[n]}\left(T_{h p_{[n]}}-T_{i[n]}\right) A_{h p}}{U_{c o n} A_{c o n} R_{h p}}\left(1+\frac{A_{h p}}{U_{c o n} A_{c o n} R_{h p}}\right)
\end{gathered}
$$

The efficiency of a pump and pump power are calculated by eqns. (4) and (5) where, $\eta_{\text {em,pump }}$ is electromechanical efficiency $90 \%$.

$$
\begin{gathered}
\varepsilon_{\text {in,pump }}=\frac{v_{\text {su,pump }} \cdot\left(\mathrm{P}_{\text {ex,pump }}-\mathrm{P}_{\text {su,pump }}\right)}{\mathrm{h}_{\text {ex,pump }}-\mathrm{h}_{\text {su,pump }}} \\
\mathrm{W}_{\text {pump }}=\frac{\dot{\mathrm{m}}\left(\mathrm{h}_{\text {out,pump }}-\mathrm{h}_{\text {in,pump }}\right)}{\eta_{\text {em,pump }} \eta_{\text {in,pump }}}
\end{gathered}
$$


Eqn. (6) shows thermal losses which is generated at the supply line in a scroll expander. In addition, the generated power of a shaft from scroll expander is calculated by eqn. (7) [4].

$$
\begin{aligned}
& \mathrm{Q}_{\mathrm{su}}=\dot{m}_{R 245 f a}\left(h_{s u}-h_{s u, 1}\right)=\left(1-e^{\left(\frac{A U_{s u}}{\dot{m} C_{p}}\right)}\right) m_{R 245 f a} C_{p}\left(T_{s u}-T_{w}\right) \\
& \mathrm{W}_{\text {exp }, \text { croll }}=\dot{\mathrm{m}}_{\mathrm{R} 245 f \mathrm{fa}}\left[\left(\mathrm{h}_{\mathrm{su}, 2}-\mathrm{h}_{\mathrm{in}}\right)+\left(\mathrm{r}_{\mathrm{v}} \mathrm{v}_{\mathrm{su}, 2}\right)\left(P_{\text {in }}-P_{e x}\right)\right]-\frac{2 \pi N \tau_{\text {loss }}}{60}
\end{aligned}
$$

Eqns. (8) and (9) represent the nominal polytropic work output of a twin screw expander as a function of its in-built volume ratio $\left(\mathrm{r}_{\mathrm{v}}\right)$ and the cycle pressure ratio $\left(\mathrm{r}_{\mathrm{p}}\right)[5]$.

$$
\begin{gathered}
\mathrm{W}_{\text {exp,screw }}=\left(\frac{P_{e x, i n}}{\rho_{e x, i n}}\right)\left(\frac{r_{v}^{1-n}-n}{1-n}-\frac{r_{v}}{r_{P}}\right) \\
\mathrm{n}=\left(\frac{a_{1}}{\log r_{v}}+\frac{a_{2}}{\log r_{v}^{2}}+\frac{a_{3}}{\log r_{v}^{3}}\right) \log r_{P}
\end{gathered}
$$

Isentropic efficiency of scroll expander and twin scroll expander is calculated by eqn. (10).

$$
\eta_{\text {isen }}=\frac{\left(h_{\text {in }}-h_{\text {out }, s}\right)}{\left(h_{\text {in }}-h_{\text {out }}\right)}
$$

Thermal and exergy efficiency of R245fa are calculated by eqns. (11) and (12).

$$
\begin{gathered}
\eta_{\mathrm{I}}=\frac{\dot{W}_{\text {exp ander }}\left(\dot{W}_{\text {pump }, \text { ORC }}+\dot{W}_{\text {pump }, \text { Con }}\right)}{\dot{Q}_{h}} \\
\eta_{\mathrm{II}}=\frac{\eta_{\mathrm{I}}}{1-\frac{T_{\text {ambient }}}{T_{\text {SolarCollector }}}}
\end{gathered}
$$

The system performance was analyzed using Table 2 that shows operating conditions of ORC system. The solar irradiance and the outdoor temperature from January to December were used to compare the expander performance according to expander type. For this, the mass flow rate of R245fa was changed at the operating condition of October. 
Table 2: Simulation condition.

\begin{tabular}{c|c}
\hline Parameters & Value \\
\hline Month & $1-12$ \\
\hline Mass flow rate of R245fa $(\mathrm{kg} / \mathrm{s})$ & $0.03,0.04,0.05^{*}, 0.06,0.07,0.08,0.09$ \\
\hline Expander inlet temperature $\left({ }^{\circ} \mathrm{C}\right)$ & $75^{\circ} \mathrm{C}^{*}$ \\
\hline Expander inlet pressure $(\mathrm{kPa})$ & $609.7^{*}$ \\
\hline
\end{tabular}

*Basic condition

\section{Results and discussion}

Fig. 3 shows the solar collector efficiency according to $\left(T_{i n}-T_{a}\right) / G$ in the solar collector of the double evacuated heat pipe. Since the variation of $\left(T_{i n}-T_{a}\right) / G$ effects on recovered available energy in a solar collector, the efficiency is proportionately decreased. When outdoor temperature is constant, an efficiency of solar collector is decreased from $73.8 \%$ to $24.4 \%$ as the inlet temperature of solar collector is gradually increased. At the inlet of solar collector, collector efficiency decreases as the inlet temperature of working fluid increases. It is due to decrease of thermal capacity in a solar collector. In this study, the system performance of Rankine cycle using R245fa and double evacuated solar collector using heat pipe which has this thermal efficiency characteristic was predicted.

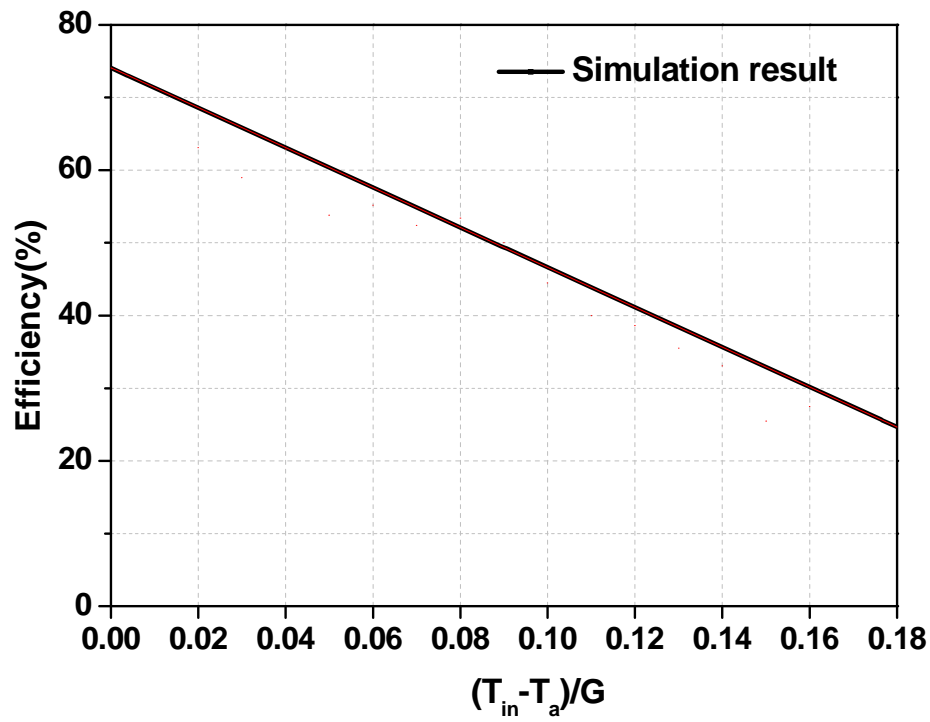

Figure 3: Efficiency variation of the glass evacuated tube solar collector using heat pipe. 
Fig. 4 shows the variations of outlet temperature and thermal capacity according to annual average solar radiation and outdoor temperature for each month. In August, the outdoor temperature is the highest, while collector discharge temperature is $97.64^{\circ} \mathrm{C}$ which is the highest one in October. The discharge temperature of solar collector at October is about $19^{\circ} \mathrm{C}$ higher than that of December. Besides, the thermal capability of solar collector is $4.9 \mathrm{~kW}$ higher than that of December. Although the outdoor temperature is the highest at August, the outlet temperature of solar collector and thermal capacity is relatively lower than October because the solar irradiance decreases due to raining season.

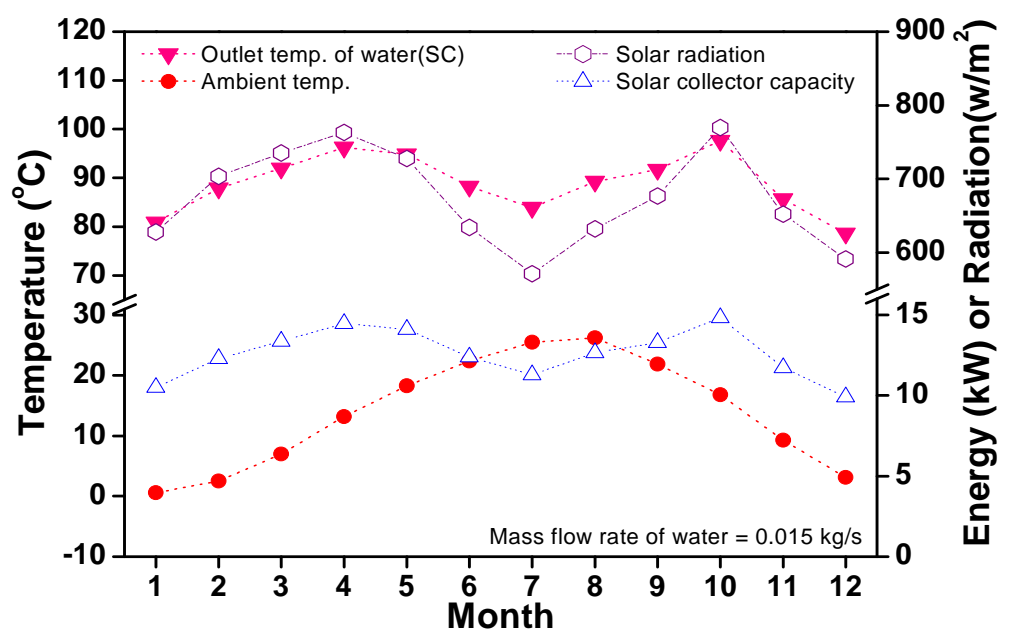

Figure 4: Variations of outlet temperature and heat gain of solar collector, ambient temperature, and solar radiation with different months.

Fig. 5 shows the variations of outlet temperature, generated power between scroll and twin screw expander, and thermal capability of evaporator according to annual month. In this study, the supplied thermal capacity in the evaporator is same because solar collector was designed with same specifications regardless of expander type. As a result, average generated power of ORC with a scroll expander is about $8 \%$ higher than that with a twin screw one. The generated power of ORC with a scroll expander shows a large variation according to operating conditions, while that with a twin screw expander shows the small variation. Besides, the outlet temperature of scroll expander is $20 \%$ higher than that of twin screw expander.

Fig. 6 shows the variations of thermal, exergy, and isentropic efficiency according to different months in a year. The average isentropic efficiency of a scroll expander is $39.4 \%$, which is $1 \%$ higher than that of a twin screw expander. In addition, the thermal and energy efficiency of scroll expander are $1.9 \%$ and $2.2 \%$ higher than those of twin screw expander, respectively. It is because that the leakage rate and heat loss during expansion process in a twin screw expander are more than that in scroll expander. 


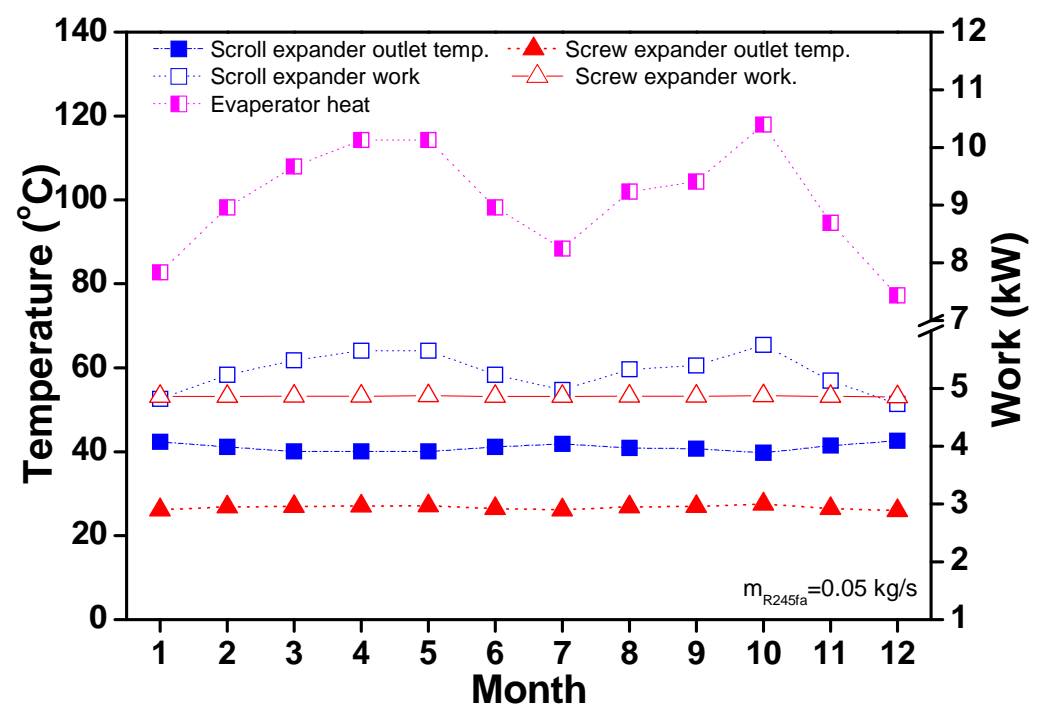

Figure 5: Variations of outlet temperature of R245fa expander, expander work and evaporator heat with different months in a year.

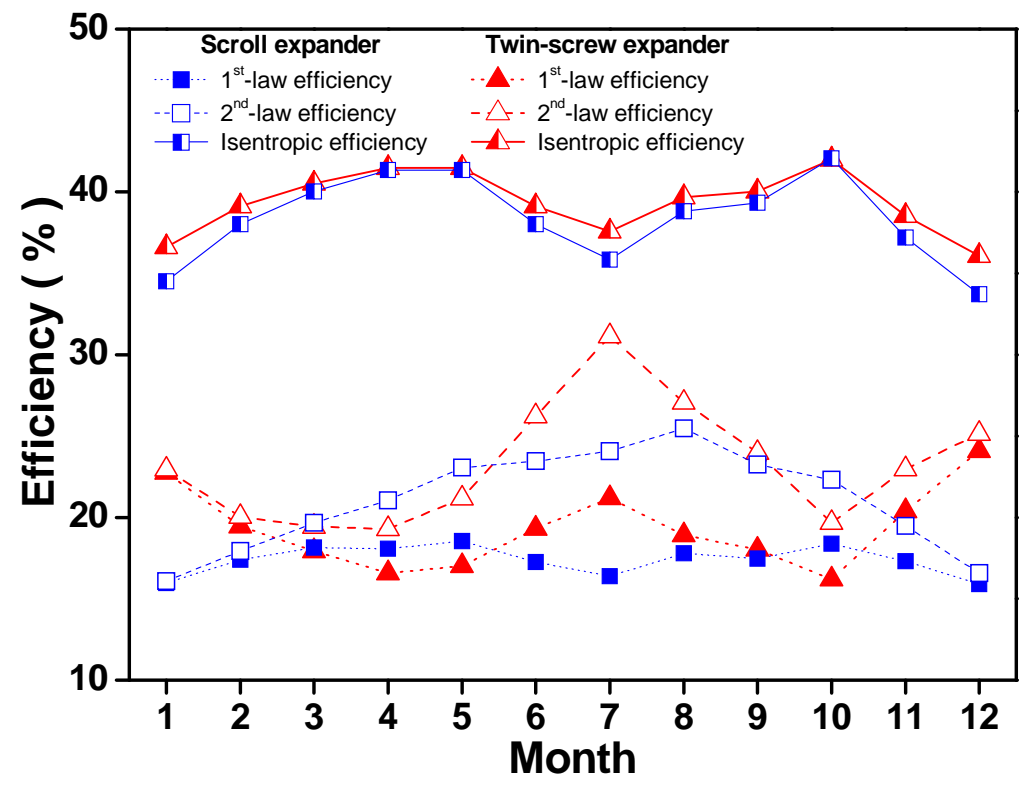

Figure 6: Variations of expander efficiency, thermal efficiency and exergy efficiency with different months in a year. 
Fig. 7 shows the variations of thermal, exergy, and isentropic efficiency according to mass flow rate of R245fa based on the operating condition of October. As the mass flow rate of R245fa increases, the isentropic efficiency of a scroll expander decreases from $42.7 \%$ to $35.2 \%$. The highest thermal and exergy of a scroll expander is $20.6 \%$ and $24.9 \%$, respectively, at the mass flow rate of 0.07 $\mathrm{kg} / \mathrm{s}$. In addition, for a twin screw expander, the isentropic efficiency is decreased from $43 \%$ to $33.1 \%$, while thermal and exergy efficiency are increased by $13.4 \%$ to $16.2 \%$ according to the increase of R245fa mass flow rate. In the research result of Du et al. [1], the system efficiency varies from $32 \%$ to $14 \%$ as the mass flow rate of working fluid changes from 0.1 to $0.7 \mathrm{~kg} / \mathrm{s}$.

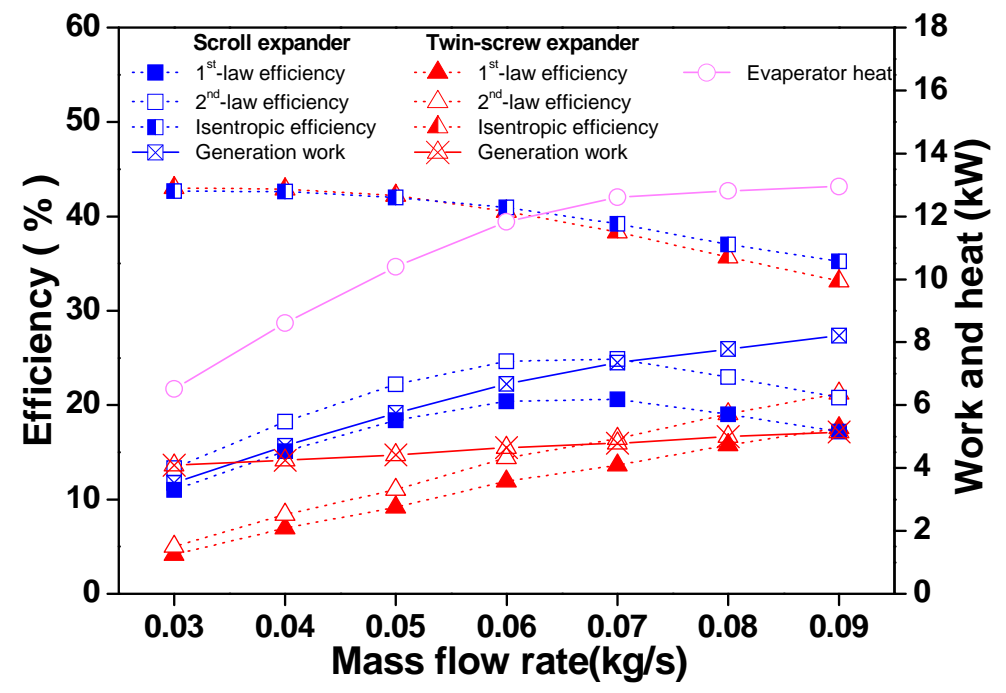

Figure 7: Variations of expander efficiency, thermal efficiency and exergy efficiency with different mass flow rate.

\section{Conclusion}

The performance of small scale solar thermal power system using R245fa Rankine cycle using scroll and twin screw expander according to operating conditions was analyzed by theoretical method. In addition, the performance comparison with expander type with a variation of mass flow rate of R245fa based on operating condition of October was carried out. The results of this study are following.

1) Under the annual monthly average solar irradiance in Gwangju, South Korea, the highest solar collector temperature was $97.6^{\circ} \mathrm{C}$ in October, which is about $19^{\circ} \mathrm{C}$ higher than that in December. Besides, the thermal capability of solar collector in October is $4.9 \mathrm{~kW}$ higher than that in December.

2) Under same operating condition, the thermal capability of evaporator is same. The generated power of ORC with a scroll expander is about $8 \%$ higher than that with a twin screw expander. 
3) The average isentropic efficiency of scroll expander is $39.4 \%$ which is $1 \%$ higher than that of twin screw expander. In addition, the thermal and exergy efficiency of scroll expander are $1.9 \%$ and $2.2 \%$ higher than those of twin screw expander, respectively.

4) As the mass flow rate of R245fa increases, the isentropic efficiency of a scroll expander decreases from $42.7 \%$ to $35.2 \%$. The highest thermal and exergy of a scroll expander is $20.6 \%$ and $24.9 \%$, respectively, at the mass flow rate of $0.07 \mathrm{~kg} / \mathrm{s}$. For a twin screw expander, the isentropic efficiency decreases from $43 \%$ to $33.1 \%$, while thermal and exergy efficiency increases by $13.4 \%$ to $16.2 \%$.

\section{Acknowledgements}

This paper is supported by the business support project "Leaders in IndustryUniversity Cooperation (LINC)”, conducted through the financial resources of the Ministry of Education, Science and Technology (MEST) and supported by the National Research Foundation of Korea (NRF).

\section{References}

[1] Du, B., Hu, E., Kolhe, M., An experimental platform for heat pipe solar collector testing. Renewable and sustainable Energy Reviews, 17, pp. 119125, 2013.

[2] Hull, J.R., Analysis of heat transfer factors for a heat pipe absorber array connected to a common manifold. Solar Energy, 108, pp. 11-6, 1986.

[3] M. O. Bamgbopa., E. Uzgoren, Numerical analysis of an organic Rankine cycle under steady and variable heat input, Applied Energy, 107, pp. 219228, 2013.

[4] Twomey, B., Jacobs, P.A., Gurgenci, H., Dynamic performance estimation of small-scale solar cogeneration with an organic Rankine cycle using a scroll expander, Applied Thermal Engineering, 51, pp. 1307-1316, 2013.

[5] Ng, K.C., Bong, T.Y., Lim, T.B., A thermodynamic model for the analysis of screw expander performance. Heat Recov Syst CHP, 10, pp. 119-33, 1990.

[6] Roy, J.P., Mishara, M.K., Parametric optimization and performance analysis of a waste heat recovery system using Organic Rankine Cycle, Journal of Energy, 35(12), pp. 5049-5062, 2010.

[7] Sylvain, Q., Vincent, L., jean, L., Experimental study and modelling of organic Rankine cycle using scroll expander, Applied Energy, 87, pp. 260268, 2010.

[8] Zhang, S., Wang, H., Performance comparison and parametric optimization of subcritical Organic Rankine Cycle(ORC) and transcritical power cycle system for low-temperature geothermal power generation, Applied Energy, 88(8), pp. 2740-2754, 2011.

[9] Lemort, V., Quoilin, S., Cuevas, C., Lebrun J., Testing and modelling a scroll expander integrated into an organic Rankine cycle, Applied Thermal Engineering, 29, pp. 3094-3102, 2009. 
[10] Winandy, E., Saavedra C., Lebrun J., Experimental analysis and simplified modelling of a hermetic scroll refrigeration compressor, Applied Thermal Engineering, 22, pp. 107-120, 2002.

[11] Klein, S.A., Engineering equation solver. Middleton, WI: F-Chart Software; 2008.

[12] Tong, Y.J., Cho, H.H., Theoretical analysis of evacuated heat pipe solar collector with different tilt angle and operating conditions, Cryogenics and Refrigeration-Proceedings of ICCR2013, D-2-13, 2013.

[13] New \& Renewable Energy Data Center, Korea, http://www.kredc.net/ 